\title{
Forecasting rupiah exchange rate with learning vector quantization neural network
}

\author{
Linawati, Made Sudarma, I Putu Oka Wisnawa
}

Department of Electrical and Computer Engineering, Faculty of Engineering, Udayana University, Indonesia

\begin{tabular}{l} 
Article Info \\
\hline Article history: \\
Received Jul 23, 2019 \\
Revised Sep 26, 2019 \\
Accepted Oct 8, 2019 \\
\hline
\end{tabular}

\section{Keywords:}

Artificial neural network

Exchange rate

Forcasting

Learning vector quantization

\begin{abstract}
The classification technique and data forecasting will probably be one of the techniques that will often be needed in handling or managing big data. So, from that the author analyzes the possible development of the existing algorithms. The purpose is to find possibilities in the use of reliable algorithms in a particular field, then can be adopted and implemented to develop forecasting techniques in the future. Based on these considerations, the authors conducted experiments by applying LVQNN to conduct shortterm forecasting on daily period of the Rupiah exchange rate. The literature that is used as a reference is the discovery of architectural data classification processes that resemble forecasting techniques. So, when there is a combination of Rupiah exchange histories, it is possible to find these combinations into certain classes based on predetermined parameters and historical data combination data and forecast values in the past. In this research the factors chosen as indicators that affect the Rupiah exchange rate are the amount of exports, the amount of imports, the inflation rate and also the world oil price. In this research the highest accuracy value in the testing process for the population reached $99.0991 \%$. The increase in the percentage value of forecasting accuracy is influenced by the composition of the data. In this study the formation of data composition is influenced by distinct data. The selection of parameters which become distinct claused determines how the composition of the data will be formed. If the composition of the data is not correct, the test results will not be good. If the number of weights vector is smaller than the input data, the forecasting accuracy will decrease. Because the weight vector cannot represent data combinations that used during training or testing.
\end{abstract}

Copyright $(2020$ Institute of Advanced Engineering and Science. All rights reserved.

\footnotetext{
Corresponding Author:

Linawati,

Department of Electrical and Computer Engineering,

Faculty of Engineering,

Udayana University, Indonesia.

Email: linawati@unud.ac.id
}

\section{INTRODUCTION}

Currency exchange rate plays an important role in financial markets. Exchange rates are determined in the foreign exchange market. Exchange rate stability is one important consideration for investors to take investment policies. If the exchange rate has high fluctuations, this can affect interest rates, commodity prices and a country's economic policy [1-4]. Then, if it is continued for a long time, it will affect investment policy. Thus, some application of forecasting techniques can help to read the direction of the movement of currency exchange rates, so that it can help investors in reading investment opportunities based on a country's exchange rate factor. Therefore, the risk of failure can be minimized and profit opportunities can be optimized. 
There are several methods that can be used in analyzing and forecasting [5-15], which are classified into statistical techniques and artificial neural networks. Each of these categories has a lot of techniques and algorithms that can be chosen according to the purpose of data processing. This research has used LVQNN as an artificial neural network algorithm that has been selected to forecast the value of the Rupiah exchange rate against the US Dollar. The reason is because LVQNN has been proven to have reliability in data processing $[16,17]$.

In general, LVQN is widely used to classify digital images. Evidenced by various studies that have been done, LVQNN has advantages when compared to other algorithms. So, there are some studies that rely on LVQNN as an optimization algorithm for computing process of other algorithms [17-19]. However, LVQNN is not perfect, sometimes in certain cases LVQNN must be combined with other algorithms to achieve its best performance [16, 18-23].

In this study LVQNN will be applied to process data that is different from its common use. Previous studies the LVQNN is used to classify digital images. In this research, LVQNN is used to forecast by utilizing a numeric type of data. The similarity of LVQNN architecture with the methods commonly used in forecasting is the process of comparing data. The data compared is the current symptom data to the control class which is a documentation of past symptoms. Then this research will evaluate the use of LVQNN algorithm in processing numerical data to predict currency exchange rate, especially Indonesian Rupiah. Finally, the effect of data composition and data weight will be analysed.

\section{RESEARCH METHOD}

The research method that has been used in this study is the quasi-experimental method. This method is chosen because it is in accordance with the research objectives and the character of the data. The purposive sampling technique used has also indicated that the requirements for randomizing data for the true experimental method cannot be fulfilled, so the most appropriate methodology to choose is the quasiexperimental model.

In this research some experiments conducted to prove that LVQNN which generally used to image classification can also be used to forecast. The reason for choosing LVQNN is with consideration of previous studies that have proven the reliability of LVQNN in classifying digital images [18, 19, 22, 23]. Besides that, based on its architecture, LVQNN is suitable to be implemented as one of forecast methods.

The data which used in this study is a secondary data. The amount of data that has been used in this study as a population is 1671 rows of data. This data has been obtained from the official website of the Republic of Indonesia Trade Ministry [24]. The data consist of the exchange rate of the Indonesian Rupiah against the US Dollar, the amount of exports, the amount of imports, the inflation rates, and the world oil prices (ORB Price). In addition, this data has been included as an Indonesian economic indicator [24].

There were several experimental models that carried out in this research. The first experimental model applied as the controller part in the quasi-experimental model. In this model the training and testing process of LVQNN are carried out with pure training data and pure testing data. Then, in the next experiment, data treatment has been done by adding weight data to the training data and testing data. The purpose is to add the data variant. Another treatment in this research is to arrange the selection of parameters which is used to perform distinct data. Therefore the composition of the weighting data, training data and testing data are changed according to the chosen parameter to be distinct parametric. The treatments are part of the quasi-experimental model. So that we can obtain comparison measures from experiments that have been carried out on the control elements in the study.

Table 1 shows an example of the data used in the study. In this table, there are five parameters that will affect forecast result based on the input symptom data. Before the data in Table 1 is processed in the LVQNN Algorithm, this data will be filtered using the distinct technique. Distinct in this research is the process of grouping data using certain parameters. This process is used to get different values from the data. These different values will later be used as weighting data, while the rest will be as input data. This process can be done separately by using SQL queries, but in this study this distinct process is used as part of a computing process that runs sequentially.

This process will produce two new tables, namely Table 3 which contains the weight data and Table 2 which acts as input data. The purpose of distinct data is to get groups of data that can be used as weighting data, and separate them from groups of data that act as input data. 
Table 1. Indonesian Economic Indicator Data and ORB Price for Rupiah Exchange Rate Forecast period 2010-2018 [24, 25]

\begin{tabular}{|c|c|c|c|c|c|}
\hline $\begin{array}{l}\text { IDR Exchange } \\
\text { Rate }\end{array}$ & Amount of Export & $\begin{array}{l}\text { Amount of } \\
\text { Import }\end{array}$ & Inflation & ORB Price & $\begin{array}{l}\text { IDR Exchange Rate } \\
\text { Prediction }\end{array}$ \\
\hline IDR/1USD & Juta US\$ & Juta US\$ & - & US\$ & IDR/1USD \\
\hline 8924 & 12181.6 & 9654.1 & 0.44 & 74.04 & 8924 \\
\hline 8924 & 12181.6 & 9654.1 & 0.44 & 75.54 & 8924 \\
\hline 8924 & 12181.6 & 9654.1 & 0.44 & 75.37 & 8924 \\
\hline 8924 & 12181.6 & 9654.1 & 0.44 & 75.49 & 8924 \\
\hline 8928 & 14399.6 & 12120 & 0.06 & 81.07 & 8928 \\
\hline 9802 & 16133.4 & 14770.3 & -0.03 & 102.75 & 9802 \\
\hline 9802 & 16133.4 & 14770.3 & -0.03 & 102.11 & 9802 \\
\hline
\end{tabular}

Table 2. Example of Input Data as the Result from Distinct

\begin{tabular}{|c|c|c|c|c|c|}
\hline $\begin{array}{c}\text { IDR Exchange } \\
\text { Rate } \\
\text { IDR/1USD } \\
\end{array}$ & $\begin{array}{c}\text { Amount of Export } \\
\text { Juta US\$ }\end{array}$ & $\begin{array}{l}\text { Amount of } \\
\text { Import } \\
\text { Juta US\$ }\end{array}$ & $\begin{array}{c}\text { Inflation } \\
- \\
\end{array}$ & $\begin{array}{c}\text { ORB Price } \\
\text { US\$ }\end{array}$ & $\begin{array}{c}\text { IDR Exchange } \\
\text { Rate Prediction } \\
\text { IDR/1USD }\end{array}$ \\
\hline 8924 & 12181.6 & 9654.1 & 0.44 & 74.04 & 8924 \\
\hline 8924 & 12181.6 & 9654.1 & 0.44 & 75.54 & 8924 \\
\hline 8924 & 12181.6 & 9654.1 & 0.44 & 75.37 & 8924 \\
\hline 9802 & 16133.4 & 14770.3 & -0.03 & 102.11 & 9802 \\
\hline
\end{tabular}

Table 3. Example of Weight Data as the Result from Distinct

\begin{tabular}{cccccc}
\hline $\begin{array}{c}\text { IDR Exchange } \\
\text { Rate }\end{array}$ & Amount of Export & Amount of & Inflation & ORB Price & \multicolumn{2}{c}{$\begin{array}{c}\text { IDR Exchange Rate } \\
\text { Prediction }\end{array}$} \\
IDR/1USD & Juta US\$ & Juta US\$ & - & US\$ & IDR/1USD \\
\hline 8924 & 12181.6 & 9654.1 & 0.44 & 75.49 & 8924 \\
8928 & 14399.6 & 12120 & 0.06 & 81.07 & 8928 \\
9802 & 16133.4 & 14770.3 & -0.03 & 102.75 & 9802 \\
\hline
\end{tabular}

The computing process will take place based on the LVQNN computing architecture. This process begins by comparing each input data to each weight data. In the LVQNN model this process is termed the calculation of the Euclidean distance value. This Euclidean distance value will determine which weight will be updated and how the weight data will be updated.

There are six experimental models that are tested in this study. The first model is an experiment that used Rupiah exchange rate as distinct parameters. This model also applies pure training data and pure testing data. The second model adds weight data into the input vector in the training process. The third model adds weight data into the input vector in the training process and also in the testing process. However, in the fourth model until the sixth model utilizes ORB price as distinct parameters. In the fourth models only use pure training data and pure test data the same as the first experiment. The fifth model adds weight data into the input data at training process. Finally, in the last experiment the weight data is added into the input data not only in the training process, but also in the testing process.

\section{RESULTS AND ANALYSIS}

The results of the first experiment can be seen in Figure 1. If we look carefully, it can be seen that between the actual and ideal values there is a relatively high deviation. Since from the point of 793 of the data trained only a few data that seemed to have actual values that were equal to their ideal values. This can be seen in the circled graph section, where in this section there is a graph that intersects the actual value and ideal value.

In order to improve computational accuracy, the second experiment was then carried out by mixing weight data with training data. The aim is to add to the training data variant and see its effect on the results of training and testing. Unfortunately, there is no significant change in deviation value. As shown in Figure 2 , changes in graphic form do occur at some point, but not many.

In the next experiment a weighting of data on training data and testing data were combined. The purpose is to get better results from previous models. The graph of the comparison of deviation values does change, as shown in Figure 3. 


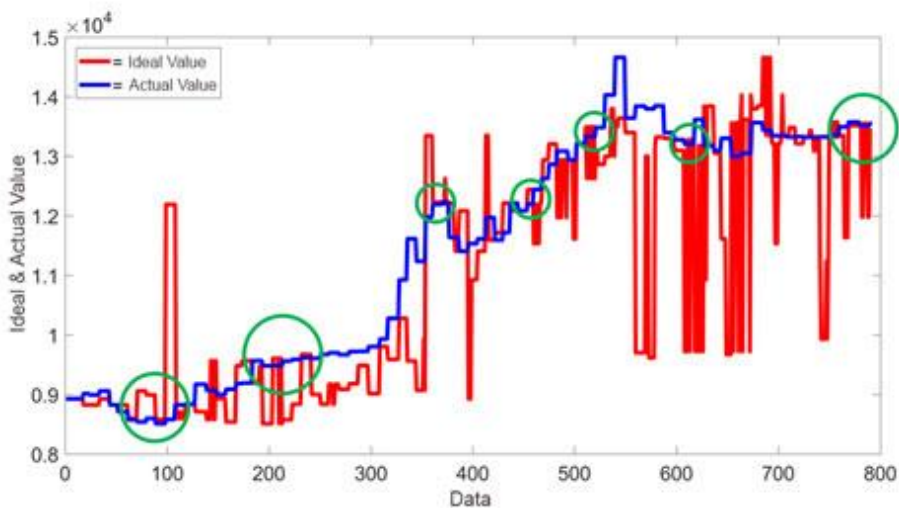

Figure 1. Deviation values of the first experimental model with rupiah exchange rate as parameters of distinct on population

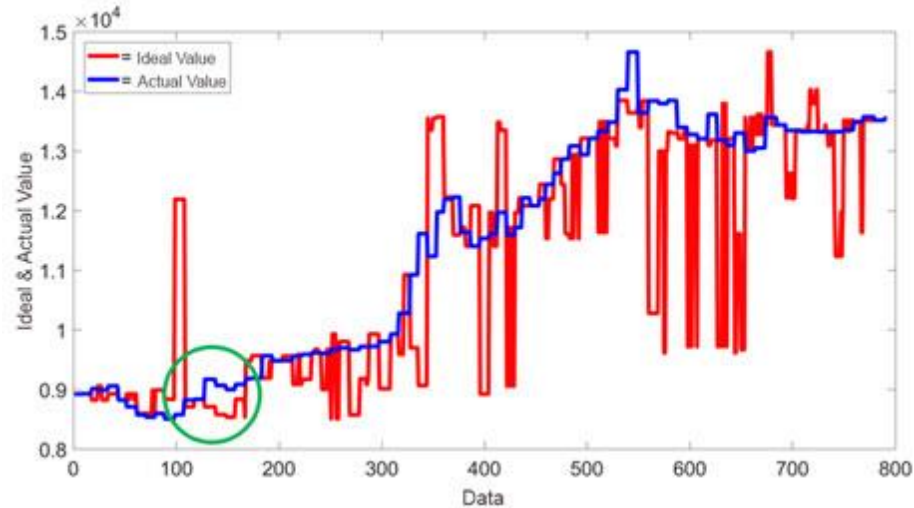

Figure 2. Deviation values of the second experimental model with rupiah exchange rate as parameters of distinct on population

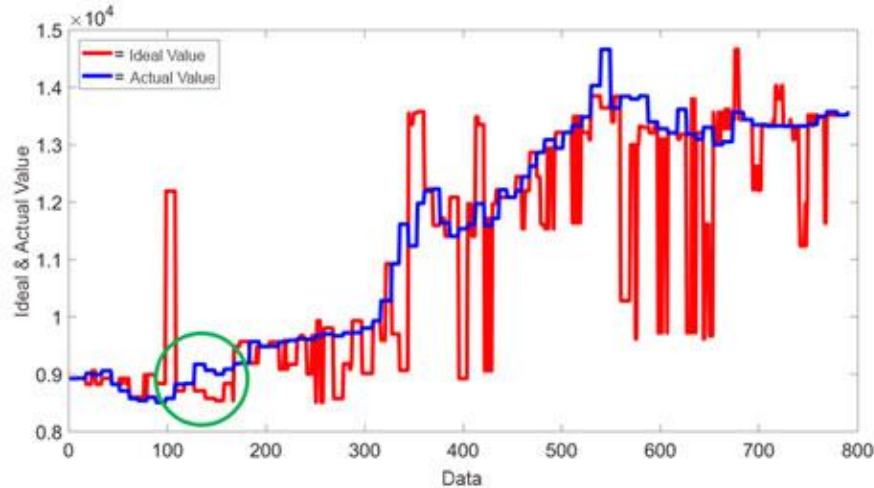

Figure 3. Deviation Values of the Third Experimental Model with Rupiah Exchange Rate as Parameters of Distinct on Population

In the fourth model, the ORB price parameter was chosen as the distinct parameter, resulting in a graph of the comparison of deviation values that was far better than the previous experimental models. The graph of actual and ideal values has aligned values as shown in Figure 4. There are some points that do not intersect on the graph, it shows there are differences in actual and ideal values. However, the amount of deviation is not high. The value is still relatively low and in line with the actual value graph.

Forecasting rupiah exchange rate with learning vector quantization neural network (Linawati) 
The results of accuracy on the fourth model have shown significant accuracy improvements. However, to get a constant value, the same treatment is given to the next model. Therefore, in the fifth experimental model, the addition of weight data to the training data was applied-The results of this model can be seen in Figure 5. The figure showed the comparison chart of the actual and ideal values. The graph which shown in Figure 5 has a shape that similar to Figure 4. However, if we see in detail, there are differences between the actual and ideal values at some points in the graphs.

In the last experiment, we added weight data to the testing data. The comparison chart of actual and ideal values displays a graph that is almost perfect. There are several differences in actual values and ideal values on some points, but the value is relatively small, as shown in Figure 6. When compared with the values of the previous model, there appears to be an increase in the quality of computing. Not only does the deviation value decrease, there is also an increase in the percentage of accuracy. Similar to the value movement in the previous experimental model, in this model an increase in value occurs gradually as a result of the solutions offered in each experimental model with the same treatment.

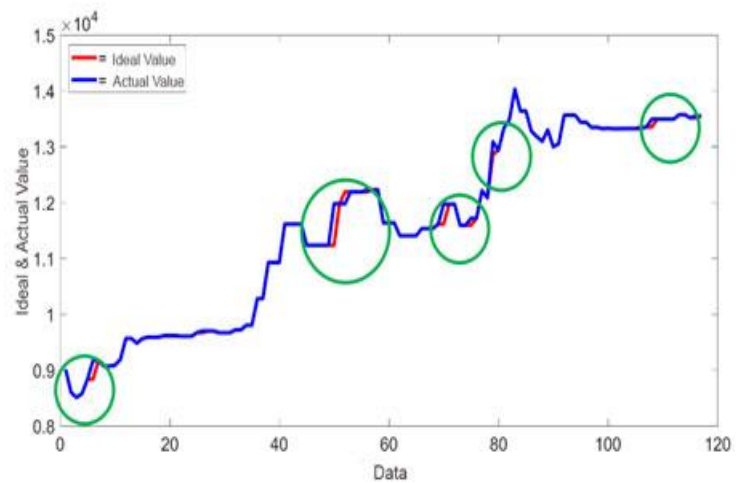

Figure 4. Deviation values of the fourth experimental model with orb price as parameters of distinct on population

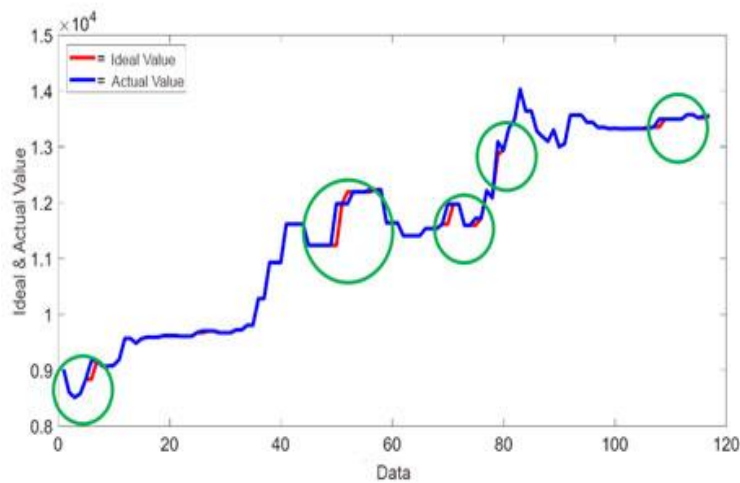

Figure 5. Deviation values of the fifth experimental model with orb price as parameters of distinct on population

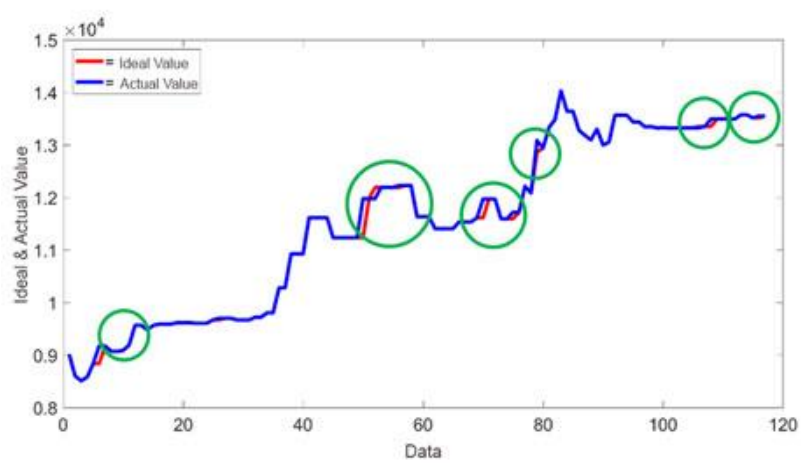

Figure 6. Deviation values of the sixth experimental model with orb price as parameters of distinct on population

Through the data which presented in Table 4, it can be seen the lowest percentage accuracy ratio and the highest of the testing process on population data. The lowest percentage accuracy value is owned by the first experiment model, which is a model with the Rupiah exchange rate as the distinct parameter. This model produces an accuracy percentage value of $6.053 \%$ that used pure training data and pure testing data. While the experimental model which has the highest percentage accuracy value is owned by the sixth model. This model used ORB price as the distinct parameter, which produces an accuracy percentage of $99.0991 \%$. This accuracy value is obtained by adding weight data into the training and testing process, to enrich the variety of data. 
As shown in Table 4, the results of testing of several sample models also show a similar pattern. The sampling method used in this study was the purposive sampling method. Population data are divided into three parts to get a sample with a small amount of data, a sample with a medium number of data, and a sample with the same amount of data as the population. The purpose of this data sampling is to make observations on the value of the deviation and the level of accuracy of forecasting on different amounts of data. The results show a pattern that is relatively the same as the results of testing of the population. The amount of data used as training data or test data seems to affect the results of forecasting. In forecasting with pure test data displayed in the First Experiment Model, the forecasting accuracy value is very small. However, by selecting the appropriate distinct parameters, this increases accuracy or can be relatively controlled as in the Fourth Experiment Model.

Table 4. RMSD Value and Accuracy Percentage in the Testing Process

\begin{tabular}{|c|c|c|c|c|c|c|}
\hline & \multirow[b]{2}{*}{$\begin{array}{l}\text { Exp. } \\
\text { Model }\end{array}$} & \multicolumn{3}{|c|}{ Amount of data } & \multirow[b]{2}{*}{$\begin{array}{c}\text { RMSD } \\
\text { Value }\end{array}$} & \multirow[b]{2}{*}{$\begin{array}{c}\text { Accurate } \\
(\%)\end{array}$} \\
\hline & & $\begin{array}{c}\text { Amount of } \\
\text { Weight Data }\end{array}$ & $\begin{array}{c}\text { Amount of } \\
\text { Training Data }\end{array}$ & $\begin{array}{c}\text { Amount of } \\
\text { Testing Data }\end{array}$ & & \\
\hline \multirow{6}{*}{ 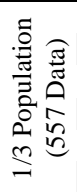 } & Model 1 & 28 & 265 & 264 & 102813.284 & 16.604 \\
\hline & Model 2 & 28 & 293 & 264 & 70101.583 & 16.724 \\
\hline & Model 3 & 28 & 293 & 292 & 70218.065 & 20.819 \\
\hline & Model 4 & 501 & 28 & 28 & 4036.036 & 92.857 \\
\hline & Model 5 & 501 & 529 & 28 & 3948.533 & 94.915 \\
\hline & Model 6 & 501 & 529 & 529 & 213.628 & 99.622 \\
\hline \multirow{6}{*}{ 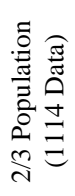 } & Model 1 & 58 & 528 & 528 & 1758100.136 & 13.826 \\
\hline & Model 2 & 58 & 586 & 528 & 2437133.366 & 11.092 \\
\hline & Model 3 & 58 & 586 & 586 & 2412185.043 & 12.116 \\
\hline & Model 4 & 950 & 82 & 82 & 11027.463 & 90.244 \\
\hline & Model 5 & 950 & 1032 & 82 & 10241.389 & 97.171 \\
\hline & Model 6 & 950 & 1032 & 1032 & 876.213 & 99.225 \\
\hline \multirow{6}{*}{ 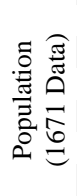 } & Model 1 & 86 & 793 & 792 & 1377391.420 & 6.053 \\
\hline & Model 2 & 86 & 879 & 792 & 1212421.746 & 10.580 \\
\hline & Model 3 & 86 & 879 & 878 & 1207483.005 & 13.538 \\
\hline & Model 4 & 1437 & 117 & 117 & 7915.154 & 90.598 \\
\hline & Model 5 & 1437 & 1554 & 117 & 7620.529 & 94.101 \\
\hline & Model 6 & 1437 & 1554 & 1554 & 798.687 & 99.099 \\
\hline
\end{tabular}

Comparison of the average forecasting accuracy based on the selection of parameters for distinct data also shows a significant difference. The average value of the percentage of computational accuracy tested in the sample based on the "Rupiah Exchange Rate" as the distinct parameter is $13.484 \%$. While the average value of the percentage of computational accuracy based on the "ORB Price" which chosen as the distinct parameter is $95.315 \%$. Through this comparison, it is clear that the "ORB Price" parameter results in a better level of forecasting accuracy compared to the "Predicted Rupiah Exchange" as the distinct parameter.

So, based on the facts produced through observations made during the experiment, it explains that the composition of the data greatly influences the results of forecasting. Mixing weight data on training data and test data can be a significant solution if the amount of weight data is greater than training data or test data. If the number of data weights turns out to be smaller than the training data and test data, then the percentage of accuracy will not increase significantly. The addition of weight data for training is related to the learning process. Then the results of testing after the process have also been improved. It is different from the addition of weight data for testing, which only ensure that the values in the learning process are also represented in the testing process.

One component in this study that has a major role in improving computational quality is distinct data. The selection of parameters for distinct clauses of data turns out to influence the results of forecasting, through changing the composition of the weighting data, training data and test data. Incorrect selection of parameters will reduce the percentage of forecasting accuracy. Distinct data can be used as one of the considerations to get the best composition of data on forecasting techniques with similar architectures. Distinct data are not only focused on the filtering process to ensure there is no data redundancy, but also, to provide a data composition to produce better accuracy values through a selection of filter parameters. Each combination is unique and affects computing results.

However, if the combination of values, sacrifices the composition of the weighted data on the training data and test data, the accuracy value will also decrease. If the amount of data weight is smaller than the input data, the forecasting accuracy will decrease, because the weighting data cannot represent data combinations used during training or testing. Conversely, if the amount of data weight is much greater than the input data, the forecasting accuracy will also decrease. This condition will occur if the weight data 
combinations are not represented in the training and testing data. This phenomenon is indirectly similar to the learning process, where the balance of teaching material (weight data) given and also the composition of the test material (data input) determine the level of absorption of learning and test results.

\section{CONCLUSION}

Based on the facts obtained from the research process that has been carried out, it can be concluded that the LVQNN algorithm can be used for forecasting. From the results of experiments that have been conducted, it was found that the lowest percentage of accuracy of the testing process was $6.053 \%$. Then, the highest percentage accuracy value is $99.0991 \%$. Compared based on the selection of parameters for distinct data, the percentage of computational accuracy tested in the sample based on the "Rupiah Exchange Rate" parameter has an average value of accuracy of $13,484 \%$. While the average value of the percentage of computational accuracy based on the "ORB Price" parameter chosen for distinct data is $95.315 \%$.

An increase in the percentage of accuracy is influenced by the composition of the data. In this study the formation of data composition is influenced by distinct data. The selection of parameters which become a distinct clause determines how the composition of the data will be formed. If the composition of the data is not correct, the test results will not be of good value. If the amount of data weight is smaller than the input data, the forecasting accuracy will decrease. Because weighting data cannot represent data combinations used during training or testing. When compared to the computational results of other methods used to forecast the exchange rate of a currency, the computational results of LVQNN in forecasting the Indonesian Rupiah exchange rate against the USD have a relatively good level of accuracy, reaching $99.0991 \%$ against population data (1671 lines of data).

\section{ACKNOWLEDGEMENTS}

The appreciation is delivered to the Postgraduate Program of Electrical Engineering, Udayana University that has given opportunity to perform the research, and for all parties that give support for the research.

\section{REFERENCES}

[1] T. N. Pandey, A. K. Jagadev, S. Dehuri, and S.-B. Cho, "A novel committee machine and reviews of neural network and statistical models for currency exchange rate prediction: An experimental analysis," J. King Saud Univ.-Comput. Inf. Sci., Mar. 2018.

[2] Swift, Robyn, "Measuring the Effects of Exchange Rate Changes on Investment in Australian Manufacturing Industry," The Economic Record, 2006, Blackwell Publishing, DOI: https://doi.org/10.1111/j.14754932.2006.00329.x

[3] Rashid Latief and Lin Lefen, "The Effect of Exchange Rate Volatility on International Trade and Foreign Direct Investment (FDI) in Developing Countries along "One Belt and One Road", Int. J. Financial Stud. 2018, 6, 86; DOI:10.3390/ijfs6040086

[4] Al Muntasir, "Portfolio Investment and Its Impact on Exchange Rate and Composite Stock Index Volatility in Indonesia," Bulletin of Monetary, Economics and Banking, Volume 17, Number 4, April 2015, pp. 415-436.

[5] H. M. Rahman, N. Arbaiy, R. Efendi, and C. C. Wen, "Forecasting ASEAN countries exchange rates using auto regression model based on triangular fuzzy number," Indones. J. Electr. Eng. Comput. Sci., vol. 14, no. 3, pp. 1525-1532, Jun. 2019.

[6] P. H. D. A. Samad, S. Mutalib, and S. Abdul-Rahman, "Analytics of stock market prices based on machine learning algorithms,” Indones. J. Electr. Eng. Comput. Sci., vol. 16, no. 2, pp. 1050-1058, Nov. 2019.

[7] E. A. Abdullah, S. M. Zahari, S. S. R. Shariff, and M. A. A. Rahim, "Modelling volatility of Kuala Lumpur composite index (KLCI) using SV and garch models," Indones. J. Electr. Eng. Comput. Sci., vol. 13, no. 3, pp. 1087-1094, Mar. 2019.

[8] M. Rout, B. Majhi, R. Majhi, and G. Panda, "Forecasting of currency exchange rates using an adaptive ARMA model with differential evolution based training," J. King Saud Univ. - Comput. Inf. Sci., vol. 26, no. 1, pp. 7-18, Jan. 2014.

[9] Akhter Mohiuddin Rather, "Computational intelligence based hybrid approach for forecasting currency exchange rate," 2015 IEEE 2nd International Conference on Recent Trends in Information Systems (ReTIS).

[10] Svitlana Galeshchuk, Yves Demazeau, "Forecasting hungarian forint exchange rate with convolutional neural networks," 2017 IEEE International Conference on Behavioral, Economic, Socio-cultural Computing (BESC).

[11] Thi Thu Huong Dinh, Van Truong Vu, Thu Lam Bui, "A multi-objective ensemble learning approach based on the non-dominated sorting differential evolution for forecasting currency exchange rates", 2016 IEEE Eighth International Conference on Knowledge and Systems Engineering (KSE). 
[12] Jui-Fang Chang, Chi-Ming Kuan, Yu-Wen Lin, "Forecasting Exchange Rates by Genetic Algorithms Based Back Propagation Network Model", 2009 IEEE Fifth International Conference on Intelligent Information Hiding and Multimedia Signal Processing.

[13] Chukiat Worasucheep, "Forecasting currency exchange rates with an Artificial Bee Colony-optimized neural network", 2015 IEEE Congress on Evolutionary Computation (CEC).

[14] Supakit Nootyaskool ; Wuttichow Choengtong, "Hidden Markov Models predict foreign exchange rate", 2014 IEEE 14th International Symposium on Communications and Information Technologies (ISCIT).

[15] Mark J. Embrechts, Christopher J. Gatti, Jonathan Linton, Thiemo Gruber, Bernhard Sick, "Forecasting exchange rates with ensemble neural networks and ensemble K-PLS: A case study for the US Dollar per Indian Rupee", IEEE The 2012 International Joint Conference on Neural Networks (IJCNN).

[16] Permana, N. E. Rozanda, F. Syafria, and F. N. Salisah, "Optimization Learning Vector Quantization Using Genetic Algorithm for Detection of Diabetics," Indones. J. Electr. Eng. Comput. Sci., vol. 12, no. 3, pp. 1111-1116, Dec. 2018.

[17] P. Frasconi, M. Gori, and G. Soda, "Links between LVQ and Backpropagation," Elsevier Sci. BV, vol. 18, pp. 303-310, Apr. 1997.

[18] F. An, X. Zhang, L. Chen, and H. J. Mattausch, "A Memory-Based Modular Architecture for SOM and LVQ with Dynamic Configuration,” IEEE Trans. Multi-Scale Comput. Syst., vol. 2, no. 4, pp. 234-241, Oct. 2016.

[19] C. D'Elia, S. Ruscino, M. Abbate, B. Aiazzi, S. Baronti, and L. Alparone, "SAR Image Classification Through Information-Theoretic Textural Features, MRF Segmentation, and Object-Oriented Learning Vector Quantization," IEEE J. Sel. Top. Appl. Earth Obs. Remote Sens., vol. 7, no. 4, pp. 1116-1126, Apr. 2014.

[20] V. B. Semwal and G. C. Nandi, "Toward Developing a Computational Model for Bipedal Push Recovery," IEEE Sens. J., vol. 15, no. 4, pp. 2021-2022, Apr. 2015.

[21] P. Podržaj and A. Čebular, "The Application of LVQ Neural Network for Weld Strength Evaluation of RF-Welded Plastic Materials," IEEEASME Trans. Mechatron., vol. 21, no. 2, pp. 1063-1071, Apr. 2016.

[22] Z. Wang, N. M. Nasrabadi, and T. S. Huang, "Spectral Classification of Hyperspectral Images Using Discriminative Dictionary Designed by Learning Vector Quantization," IEEE Trans. Geosci. Remote Sens., vol. 52, no. 8, pp. 4808-4822, Aug. 2014.

[23] Demirhan, M. Törü, and İ. Güler, "Segmentation of Tumor and Edema Along With Healthy Tissues of Brain Using Wavelets and Neural Networks," IEEE J. Biomed. Health Inform., vol. 19, no. 4, pp. 1451-1458, Jul. 2015.

[24] "Indikator Ekonomi Indonesia Kementerian Perdagangan Republik Indonesia," kemendag.go.id. [Online]. Available: http://www.kemendag.go.id/id. [Accessed: 04-May-2018].

[25] "OPEC: OPEC Basket Price." [Online]. Available: http://www.opec.org/opec_web/en/data_graphs/40.htm. [Accessed: 04-May-2018].

\section{BIOGRAPHIES OF AUTHORS}

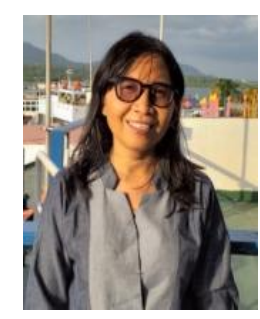

Linawati hold PhD majoring telecommunications engineering from the University of New South Wales, Sydney, Australia in 2004. She was an Executive Director of Global Development Learning Network (GDLN) 2006 - 2014, and Head of ICT of Udayana University in 2007 2014. She is head of electrical engineering postgraduate study program, Udayana University from 2017 - now and IEEE member.

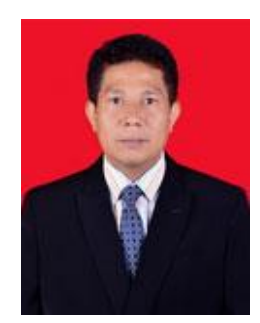

Sudarma is a senior lecturer at Department of Electrical and Computer Engineering, Udayana University, Bukit Jimbaran Campus, Bali, Indonesia. He is IEEE member.

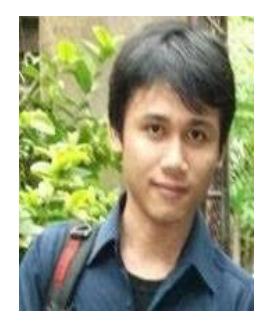

I Putu Oka Wisnawa is postgraduate student in Electrical Engineering Department, Udayana University, Bali, Indonesia. His research interest is system modeling, artificial intelligency, and big data. 